\title{
LA LEY ORGÁNICA \\ DE ESTABILIDAD PRESUPUESTARIA Y SOSTENIBILIDAD FINANCIERA. LA EXIGENCIA DE ESTABILIDAD PRESUPUESTARIA DEL SECTOR PÚBLICO
}

ADORACIÓN GALERA VICTORIA 
SUMARIO

1. INTRODUCCIÓN. 2. PRINCIPIOS GENERALES. 3. LA INSTRUMENTACIÓN DE LOS PRINCIPIOS DE ESTABILIDAD PRESUPUESTARIA Y SOSTENIBILIDAD FINANCIERA. 4. MEDIDAS PREVENTIVAS, CORRECTIVAS Y COERCITIVAS. 5. GESTIÓN PRESUPUESTARIA. 6. CONCLUSIONES. 


\title{
LA LEY ORGÁNICA DE ESTABILIDAD PRESUPUESTARIA Y SOSTENIBILIDAD FINANCIERA. LA EXIGENCIA DE ESTABILIDAD PRESUPUESTARIA DEL SECTOR PÚBLICO
}

\author{
ADORACIÓN GALERA VICTORIA \\ Profesora Contratada Doctora de Derecho Constitucional \\ Universidad de Granada
}

\section{INTRODUCCIÓN}

Una de las novedades legislativas aprobadas en el contexto económico actual, ha sido la Ley Orgánica 2/2012, de 27 de abril, de Estabilidad Presupuestaria y Sostenibilidad Financiera (LOEPSF) ${ }^{1}$ de desarrollo de los principios constitucionales del nuevo artículo 135 de la Constitución, que consagra a nivel interno el compromiso de estabilidad presupuestaria y limitación de la deuda

${ }^{1}$ La LOEPSF sería modificada por la Ley Orgánica 4/2012, de 28 de septiembre, con el fin de permitir la prórroga de los plazos para acceder a los mecanismos extraordinarios de liquidez e incrementar los mecanismos de información sobre los Planes de ajuste de las Comunidades Autónomas y las Corporaciones Locales (disposición adicional primera). Por otra parte, la reforma legislativa incorpora una nueva disposición con el fin de reforzar las garantías del pago del vencimiento de la deuda financiera (disposición adicional cuarta). Por último, la reforma legislativa pretende esclarecer la forma en que se computa la Deuda Pública de las administraciones públicas que se adhieran a los mecanismos adicionales de financiación. 
pública asumido en el ámbito europeo ${ }^{2}$. En efecto, el origen de la Ley Orgánica de Estabilidad Presupuestaria y Sostenibilidad Financiera se encuentra en la reforma de la Constitución aprobada el 27 de septiembre de 2011, mediante la cual se incorpora con rango constitucional el principio de estabilidad presupuestaria y se "prescribe un programa constitucional obligatorio para la actividad financiera pública» ${ }^{3}$, indisponible para las administraciones públicas ${ }^{4}$.

Se trata, pues, de una actuación legislativa cuyo fundamento se encuentra ahora directamente en la Constitución ${ }^{5}$, que pretende además dar cobertura nor-

${ }^{2}$ La reforma calificada en no pocas ocasiones como innecesaria, tramitada por el procedimiento de urgencia y mediante lectura única, ha sido duramente criticada desde el punto de vista técnico, tanto por su contenido como por el procedimiento elegido para su aprobación. Esos y otros aspectos serían tomados en consideración en la encuesta sobre «La reforma del artículo 135 CE» publicada en la Revista Española de Derecho Constitucional, núm. 93, 2011, donde se contiene la respuesta inmediata de los profesores E. ÁLVAREZ CONDE, (pp. 160 y ss.); E. ALBERTÍ ROVIRA (pp. 164 y ss.); M. ARAGÓN (pp. 169 y ss.); F. J. BATIDA, (pp. 172 y ss). G. CÁMARA VILLAR (pp.176 y ss), F. DE CARRERAS SERRA (pp. 181 y ss.); J. L. CASCAJO CASTRO (pp. 192 y ss.); J. DE ESTEBAN, (195 y ss.); J. PÉREZ ROYO (pp. 198 y ss.); F. RUBIO LLORENTE (pp. 203 y ss.). Asimismo, vid. R. FALCÓN Y TELLA, Revista General de Derecho Europeo, no 25, 2011, pp. 1 y ss., disponible en www.iustel.com/v2/revistas/; como los trabajos de R. BLANCO VALDÉS «La reforma de 2011» y J. TAJADURA, «Reforma constitucional e integración europea», ambos en Claves de Razón Práctica, núm. 216, 2011, pp. 8 y ss y 20 y ss. respectivamente. Unas valoraciones posteriores vid. entre otros, A. EMBID IRUJO, La constitucionalización de la crisis económica, Iustel, 2012, en especial, pp. 62 y ss; y las reflexiones de los profesores M. CONTRERAS CASADO, E. GARCÍA LÓPEZ, J. C. GAVARA DE CARA, A. LÓPEZ BASAGUREN, A. LÓPEZ PINA (pp. 11 y ss.) y P. KIRCHHOF (pp. 77 y ss.), con ocasión de la encuesta publicada en el número monográfico sobre «La reforma constitucional» de Teoría y Realidad Constitucional, núm. 29, 2012, así como los estudios sobre la reforma del artículo 135 CE publicados en este mismo número de M. MEDINA GUERRERO «La reforma del artículo 135 de la Constitución» (pp. 131 y ss.); P. GARCÍA ESCUDERO. «La inadmisión de enmiendas a la reforma del artículo 135 de la Constitución» (pp. 165 y ss.); J. F. LÓPEZ AGUILAR. «De la Constitución "irreformable" a la reforma constitucional "exprés” (pp. 199 y ss.); M. ${ }^{a} J$. RIDAURA MARTÍNEZ. «La reforma del artículo 135 de la Constitución. ¿Pueden los mercados quebrar el consenso constitucional?» (pp. 237 y ss.); E. BELDA PÉREZ-PEDRERO. «Los límites a la reforma constitucional» (pp. 261 y ss.); O. SALAZAR BENÍTEZ «Algunas notas críticas sobre la reforma del art. 135 CE.» (pp.405 y ss.). Asimismo, cfr. J. F. SÁNCHEZ BARRILAO «La crisis de la deuda soberana y la reforma del artículo 135 de la Constitución Española» (en prensa).

3 Dictamen 164/2012, de 1 de marzo, del Consejo de Estado, al anteproyecto de LOEPSF (apartado IV D).

${ }^{4}$ Como afirma el Tribunal Constitucional, «en su sentido principial, queda fuera de la disponibilidad — de la competencia — del Estado y de las Comunidades Autónomas. Cuestión distinta es la de su desarrollo, pues aquel sentido principal admite diversas formulaciones, de modo que será ese desarrollo el que perfilará su contenido» (STC 157/2011/3).

5 La competencia estatal para dictar normas orgánicas en materia de estabilidad presupuestaria ya había sido admitida sobre la base del artículo 149.1.11. ${ }^{a}, 13 .^{a}, 14{ }^{a}$ y $18 .^{a}$ de la Constitución 
mativa a los compromisos adoptados en materia de estabilidad presupuestaria con los se pretende reforzar el pilar económico de la Unión Económica y Monetaria. La ley orgánica establece las reglas y mecanismos de garantía del cumplimiento de los límites del déficit público estructural en nuestro país y desarrolla los objetivos de limitación de la deuda pública y, en general, los elementos esenciales del nuevo marco europeo de estabilidad financiera y gobernanza económica fijado por el Tratado de Estabilidad, Coordinación y Gobernanza en la Unión Europea, firmado el 2 de marzo de $2012^{6}$. La ley orgánica ejecuta así un mandato constitucional en un contexto político y económico que potencia el fortalecimiento de la estabilidad presupuestaria en el ámbito europeo.

Según su preámbulo, los objetivos básicos de la norma son: a) garantizar la sostenibilidad financiera de todas las Administraciones Públicas, b) fortalecer la confianza en la estabilidad de la economía española y c) reforzar el compromiso de España con la Unión Europea en materia de estabilidad presupuestaria. Con ello se pretende «consolidar el marco de la política económica orientada al crecimiento económico y la creación del empleo». Para ello el legislador arroja claridad a la regulación en materia de estabilidad presupuestaria y sostenibilidad financiera al recoger en un texto único de treinta y dos artículos dicha disciplina ${ }^{7}$. Como también esta ley dota de instrumentos suficientes con los que

(STC 134/2011/7). Una vez realizada la reforma constitucional del artículo 135 CE, la atribución a una ley orgánica del desarrollo del principio de estabilidad presupuestaria confirma la competencia del Estado en esta materia (STC 157/2011/3).

${ }^{6}$ Para unas valoraciones iniciales sobre el contenido y peculiar naturaleza del Tratado de Estabilidad, Coordinación y Gobernanza en la Unión Económica y Monetaria previas a su firma por todos los Estados miembros, salvo Reino Unido y República Checa, cfr, F. STEINBERG e I. MOLINA, «Un renovado pacto de estabilidad (¿sin crecimiento?) para la UE», ARI 161/2011 (15/12/2011), Europa /Economía y Comercio Internacional en Real Instituto Elcano; J. M. MARTÍN y PÉREZ DE NANCLARES, «El nuevo tratado para reforzar la unión económica: una "cura de urgencia" excepcional y transitoria», en ARI 1/2012 (10/01/2012), Europa, en Real Instituto Elcano; ambos trabajos disponibles en www.realinstitutoelcano.org. Para unas primeras reflexiones sobre el texto ya aprobado, C. CLOSA, «Jugando a ratificar: las reglas de entrada en vigor del nuevo Tratado de Estabilidad, Coordinación y Gobernanza del euro», en ARI 15/2012 (07/03/2012), Europa, en Real Instituto Elcano, disponibles igualmente en www.realinstitutoelcano.org; Además del texto del Tratado, la LOEPSF refleja el contenido de normas de derecho derivado, en particular, los Reglamentos n ${ }^{\circ}$ 1466/1997 y 1467/1997, del Consejo, de 7 de julio, modificados por los Reglamentos no $1175 / 2011$ y 1177/201 y la Directiva 2011/85/UE.

7 Conforme a la Disposición Derogatoria de la LOEPSF, queda derogada expresamente la Ley Orgánica 5/2001, de 13 de diciembre, complementaria de la Ley General de Estabilidad Presupuestaria y el Texto Refundido de la Ley General Presupuestaria, aprobado por Real Decreto Legislativo $2 / 2007$, de 28 de diciembre. Además, contiene una cláusula general en virtud de la cual quedan derogadas cuantas disposiciones se opongan a la regulación contenida en la ley orgánica. 
afrontar los retos de estabilidad presupuestaria y sostenibilidad financiera que deben inspirar la actividad de las administraciones públicas.

Estructurada en seis capítulos, la regulación orgánica establece los principios rectores y los procedimientos necesarios para la aplicación efectiva de los principios de estabilidad presupuestaria y sostenibilidad financiera (artículo 1 LOEPSF). El ámbito subjetivo de la ley aparece delimitado por el concepto «sector público» utilizado en el Sistema Europeo de Cuentas Nacionales y Regionales ${ }^{8}$. De este modo, su ámbito de aplicación se extiende al conjunto de las administraciones públicas, esto es, al Estado y sus organismos autónomos, las Comunidades Autónomas, las Corporaciones locales, la Administración de la Seguridad Social, así como las entidades públicas empresariales, sociedades mercantiles y demás entes de derecho público dependientes de las administraciones públicas (artículo 2 LOEPSF). Además de mantener la opción legislativa ya iniciada respecto a los sujetos vinculados por el principio de estabilidad presupuestaria 9 , la vinculación de esta norma a todo el sector público pretende transmitir, siguiendo el preámbulo de la ley, «una idea de igualdad en las exigencias presupuestarias, de responsabilidad y lealtad institucional entre todas las administraciones públicas».

Ley orgánica contiene además novedades en materia de estabilidad presupuestaria, no siempre incuestionables en todos sus aspectos. Al objeto de presentar la actividad legislativa en este ámbito se seguirá la estructura de la norma, exponiendo por un lado, los cambios introducidos en el marco de los principios generales de la ley (capitulo II); por otro lado, las reglas para la instrumentación de los principios de estabilidad presupuestaria y sostenibilidad financiera (capítulo III); en tercer lugar, se analizan las medidas de carácter preventivo, correctivo y coercitivo establecidas para garantizar el cumplimiento de los objetivos de equilibrio presupuestario y de endeudamiento (capítulo IV). Por último, se destacan las normas de gestión presupuestaria con las que el legislador pretende asegurar la coherencia de la actuación de las administraciones públicas con los objetivos de estabilidad presupuestaria y deuda pública y la regla de gasto (capítulo VI). El análisis de estos contenidos conducirá, finalmente, a una valoración global sobre el alcance de esta actuación legislativa.

${ }^{8}$ Reglamento n. ${ }^{\circ}$ 2223/1996, del Consejo, de 25 de junio de 1996.

9 El artículo 2 de la Ley 18/2001, de 12 de diciembre, General de Estabilidad Presupuestaria, vigente hasta el 1 de enero de 2008, ya incorporaría en el concepto «sector público» el conjunto de administraciones públicas y grupos de agentes mencionadas en la definición del ámbito subjetivo de la ley. 


\section{PRINCIPIOS GENERALES}

Como se ha indicado, la LOEPSF desarrolla el principio constitucional de estabilidad presupuestaria reforzando, respecto a la regulación anterior, los principios de plurianualidad, eficacia y eficiencia en la asignación de los recursos públicos y ampliando considerablemente el principio de transparencia. No obstante, la principal novedad en este punto consiste en la incorporación de otros tres principios, el de sostenibilidad financiera, responsabilidad y lealtad institucional, como complemento a las exigencias constitucionales de equilibrio presupuestario y limitación del déficit público (capítulo II). Conviene destacar que el desarrollo orgánico de estos principios queda amparado de forma expresa, en el mandato constitucional en la medida en que el nuevo artículo 135 de la Constitución determina un marco de actuación respecto de los principios de estabilidad presupuestaria y sostenibilidad financiera y de responsabilidad. En cambio, el carácter orgánico de las normas relativas al resto de los principios previstos en la ley debe deducirse de forma implícita del texto constitucional, como un complemento necesario para el cumplimiento de los objetivos constitucionales de déficit y deuda pública ${ }^{10}$.

Así, además del desarrollo legislativo de los principios de estabilidad presupuestaria y sostenibilidad financiera contenido en el capítulo siguiente, el principio de estabilidad presupuestaria de las administraciones públicas es definido, de forma quizá excesivamente parca, como «la situación de equilibrio o superávit estructural» (artículo 3.2 LOEPSF). Por su parte, el principio de sostenibilidad financiera, entendido como «la capacidad para financiar compromisos de gasto presentes y futuros dentro de los límites de déficit y deuda pública (artículo 4.2)», constituye la otra cara del mismo principio orientado a lograr una situación financiera equilibrada. Es en la articulación de estos dos principios donde se advierten las novedades más importantes de la regulación orgánica, no siempre incuestionables como se expone más adelante.

En el marco de estos objetivos generales, el legislador orgánico intenta garantizar su cumplimiento sobre la base del principio de responsabilidad al

${ }^{10}$ Como afirma el Consejo de Estado, «es claro que el nuevo artículo 135 de la Constitución acota expresamente un ámbito competencial preciso, por referencia a los principios de estabilidad presupuestaria y de sostenibilidad financiera, que se concretan respectivamente en los objetivos de déficit y de volumen de deuda, y al principio de responsabilidad. No hay ese engarce explícito en el caso de los principios de plurianualidad, de transparencia, de lealtad institucional y de eficiencia en la asignación de los recursos públicos; sin embargo, su naturaleza orgánica puede justificarse por razón de que constituyen complementos necesarios para garantizar un mejor y más eficaz cumplimiento de los aludidos objetivos de deuda y déficit». Dictamen 164/2012, del Consejo de Estado (apartado V.C.2). 
delimitar el grado de responsabilidad atribuible a cada administración pública «en la parte que le sea imputable» (artículo 8.1) ${ }^{11}$. La cuestión, sin embargo, no parece fácil de precisar $y$, a posteriori, puede generar problemas prácticos a la hora de fijar la cuota de responsabilidad imputable a las administraciones públicas que generen o puedan generar el incumplimiento de los compromisos de déficit público. En todo caso, la ley reproduce el contenido previsto en la disposición adicional primera de la Ley 2/2011, de 4 de marzo de Economía Sostenible ${ }^{12}$, donde se establece un mecanismo de asignación de responsabilidad cuando ésta pudiera generar consecuencias financieras para el Estado, derivadas del incumplimiento de normas de derecho europeo. Para estos supuestos, la ley prevé repercutir en el presupuesto de la administración pública incumplidora, las sanciones económicas impuestas por las instancias europeas al Estado español. El legislador orgánico reproduce, pues, el mecanismo de repercusión para los eventuales incumplimientos de los compromisos europeos. Sin embargo, los efectos que generarían esta previsión respecto de la exigencia de responsabilidad a la administración pública incumplidora se diluyen ante la falta de concreción de su marco de aplicación.

Y es que, para justificar la presencia de estas disposiciones, el legislador debía haber precisado el ámbito de actuación del mecanismo de repercusión de responsabilidad para el cumplimiento de los compromisos europeos sobre estabilidad presupuestaria, asumidos por el Estado tras la firma del Pacto fiscal y el Tratado de Estabilidad, Coordinación y Gobernanza. Así sería advertido por el Consejo de Estado, en el sentido de indicar que, o se precisaba el ámbito de aplicación del mecanismo previsto en la disposición adicional segunda, o carecía de sentido su inclusión «por innecesaria y meramente reiterativa (...) o, cuando menos, introducirse sin carácter orgánico pues es claro que excedería del ámbito material delimitado por el artículo 135 de la Constitución» ${ }^{13}$. La opción legislativa ha sido, sin embargo, mantener inalterada la redacción inicial, con lo que ello implica de extralimitación de su ámbito de regulación.

${ }^{11}$ Conforme a este precepto, «Las Administraciones Públicas que incumplan las obligaciones contenidas en esta Ley, así como las que provoquen o contribuyan a producir el incumplimiento de los compromisos asumidos por España de acuerdo con la normativa europea, asumirán en la parte que les sea imputable las responsabilidades que de tal incumplimiento se hubieran derivado».

${ }^{12}$ La disposición adicional segunda de la LOEPSF reproduce la disposición adicional primera de la Ley 2/2011, de 4 de marzo, de Economía Sostenible. En dicha norma se faculta al Consejo de Ministros para declarar la responsabilidad y acordar la compensación o retención de la deuda, según proceda, remitiendo al posterior desarrollo reglamentario, el desarrollo de los mecanismos necesarios para garantizar la efectividad de esta regulación.

13 Dictamen 164/2012, del Consejo de Estado (apartado V.C.3). 
Finalmente, las previsiones en materia de responsabilidad se completan con el establecimiento de medidas muy severas, de carácter coercitivo (artículo 25) y de ejecución forzosa (artículo 26), con las que se pretende corregir y sancionar los incumplimientos graves de las administraciones ante las exigencias de estabilidad presupuestaria, cuestión sobre la que nos detendremos en las páginas siguientes.

Por otra parte, conviene resaltar el protagonismo que cobra el principio de transparencia, cuya instrumentación se articula sobre la exigencia de información suficiente y adecuada para verificar la situación financiera de las administraciones públicas, en aras de evitar déficit públicos excesivos conforme a los requisitos impuestos por las normas europeas (artículo 6 y capítulo V) ${ }^{14}$. Para ello, se otorga al Gobierno una posición central para recabar, proveer y publicar información sobre las cuentas públicas de todas las administraciones públicas y se prevé la posibilidad de imponer medidas automáticas de corrección ante el incumplimiento de las obligaciones de suministrar información y transparen$\mathrm{cia}^{15}$. Finalmente, la regulación del marco general de los principios de actuación de las administraciones públicas, se cierra con la previsión del principio de lealtad institucional conforme al cual las administraciones públicas, en el ejercicio legítimo de sus competencias, deben valorar y ponderar el impacto que su política presupuestaria y económico-financiera puede tener en el resto de las administraciones y, prestar la información, cooperación y apoyo necesario para el logro del objetivo de equilibrio en el conjunto del Estado (artículo 9).

\section{LA INSTRUMENTACIÓN DE LOS PRINCIPIOS DE ESTABILIDAD PRESUPUESTARIA Y SOSTENIBILIDAD FINANCIERA}

El capítulo relativo a la instrumentación de los principios de estabilidad presupuestaria y sostenibilidad financiera cobra especial protagonismo en la regulación orgánica, donde se introducen las reglas que permiten la aplicación de unos principios que traducen los presupuestos políticos y económicos que inspiran la norma. Se trata, en efecto, de la formulación jurídica de los postulados inspiradores del fortalecimiento de la disciplina económica y financiera

${ }^{14}$ Vid. al respecto, los artículos 12 y ss de la Directiva 2011/85/UE del Consejo, de 8 de noviembre de 2011, sobre los requisitos aplicables a los marcos presupuestarios de los Estados miembros.

${ }^{15}$ Conforme al artículo 27.6 LOEPSF «El incumplimiento de las obligaciones de suministro de información y transparencia derivadas de las disposiciones de esta ley podrá llevar aparejada la imposición de las medidas previstas en el artículo 20». 
con la que se pretende restaurar la situación de crecimiento económico, tanto en el ámbito europeo como en el nacional. Sorprende, sin embargo, que la articulación de estos principios dificulte de forma severa la realización de funciones básicas del Estado y termine desplazando contenidos esenciales del Estado, particularmente su carácter social. Es en el ámbito político y económico actual de la Unión Europea, donde se ha producido una radical transformación de las reglas democráticas internas de los Estados miembros y de las reglas de funcionamiento de la $\mathrm{UE}^{16}$, donde se enmarca esta actuación del legislador orgánico.

En este contexto, la estabilidad presupuestaria es concebida como «una de las claves de la política económica que contribuirá a reforzar la confianza en la economía española, facilitará la captación de financiación en mejores condiciones y, con ello, permitirá recuperar la senda del crecimiento económico y la creación de empleo» ${ }^{17}$. En el marco de estas premisas se desarrolla las reglas que permitirán la instrumentación del principio de estabilidad financiera (artículos 11 y 12), con las que se pretende dar cumplimiento al mandato constitucional. Para ello, por un lado, el legislador orgánico incorpora el mandato general dirigido al conjunto de las administraciones públicas de mantener una situación de equilibrio o superávit presupuestario. Y ello, con el consiguiente mandato de prohibición de incurrir en déficit estructural, definido como «el déficit ajustado del ciclo, neto de medidas excepcionales y temporales» (artículo 11.2). Se prevé igualmente que sólo son admisibles situaciones de déficit estructural por los motivos expresamente mencionados en la ley: catástrofes naturales, recesión económica o situaciones de emergencia extraordinaria, cuya apreciación requerirá en todo caso, el respaldo de la mayoría absoluta de los miembros del Congreso (artículo 11.3). No se fija, sin embargo, la distribución de los límites de déficit entre las distintas administraciones públicas ${ }^{18}$, estableciéndose únicamente que, en situaciones de reformas estructurales y de acuerdo con las normas europeas, «podrá alcanzarse en el conjunto de las Administraciones Públicas un déficit estructural del 0,4 por ciento del Producto Interior Bruto» (artículo 11.2). Pero, es quizás, la indeterminación de la metodología y el procedimiento para el cálculo del déficit estruc-

${ }^{16}$ Vid. al respecto, F. BALAGUER CALLEJÓN, «Presentación» y «Derecho y Justicia en el ordenamiento constitucional europeo», ambos trabajos publicados en Revista de Derecho Constitucional Europeo, núm. 16, 2011, pp. 9 y ss. y 261 y ss. respectivamente.

17 Preámbulo de la Ley Orgánica 2/2012, de 27 de abril, de Estabilidad Presupuestaria y Sostenibilidad Financiera.

18 Según el artículo 135.5 a) primer inciso de la Constitución, la ley orgánica regulará, en todo caso, «La distribución de los límites de déficit y de deuda entre las distintas Administraciones Públicas, los supuestos excepcionales de superación de los mismos y la forma y plazo de corrección de las desviaciones que sobre uno y otro pudieran producirse». 
tural, la carencia más destacada de las previsiones contenidas en esta materia. Al respecto, la ley se limita a establecer que "para el cálculo del déficit estructural se seguirá la metodología utilizada por la Comisión Europea en el marco de aplicación de la normativa de estabilidad presupuestaria» (artículo 11.6), lo que, como indicaría el Consejo de Estado en su dictamen al anteproyecto de esta ley, deja en un alto grado de indeterminación que aconsejaba establecer, al menos, las líneas generales de esa metodología, así como concretar las normas europeas sobre las que se ejerce la competencia sobre esta materia ${ }^{19}$.

Otro aspecto destacado de la norma orgánica consiste en la incorporación de la denominada regla de gasto, prevista en el Reglamento (UE) no 1175/2011 conforme a la cual el gasto público no podrá incrementarse anualmente por encima de la tasa de crecimiento de referencia del Producto Interior Bruto (artículo 12). Se trata de una regla fiscal ya contenida en una norma de derecho interno ${ }^{20}$ que, intentando corregir el elevado déficit presupuestario de las administraciones públicas, introduce un techo de gasto que limita el crecimiento anual del gasto público. La regla de gasto se incluye así como un mecanismo para reforzar otros instrumentos más tradicionales como son el equilibrio presupuestario y el límite a la deuda pública, y cuyo creciente interés en la práctica política se debe a que permite contener el déficit público ${ }^{21}$. A diferencia de la regulación anterior, el legislador orgánico extiende la regla de gasto a todas las administraciones públicas (Administración General del Estado, Comunidades Autónomas y Administraciones locales) ${ }^{22}$ e introduce novedades respecto al órgano y el cálculo de la tasa de referencia del crecimiento del PIB. Será el Ministerio de Economía y Competiti-

19 Dictamen 164/2012, del Consejo de Estado, (apartado V.C.1), conforme al cual «Es necesario precisar esa referencia excesivamente indeterminada a "la metodología utilizada por la Comisión Europea en el marco de aplicación de la normativa de estabilidad presupuestaria”, cuando menos mencionando expresamente las normas europeas en que se ampara la competencia de la Comisión. Y también deben incorporarse al anteproyecto, como mínimo, las líneas generales de esa metodología. - Han de revisarse los términos en que se remite al desarrollo reglamentario la aplicación de dicha metodología al marco nacional, pareciendo razonable que sea un Real Decreto el que aborde en un primer nivel reglamentario dicha regulación. - En fin, debe incorporarse alguna previsión sobre el procedimiento a seguir para el cálculo del déficit estructural, cuestión respecto de la que el anteproyecto guarda silencio». Ibidem (apartado VIII.B).

20 Artículo 8 bis, incorporado con la última reforma de la Ley General de Estabilidad introducida por el Real Decreto-ley 8/2011, de 7 de julio,

${ }^{21} \mathrm{Al}$ respecto, J. F. BELLOD REDONDO, «Techo de Gasto y estabilidad presupuestaria», en Presupuesto y Gasto Público, núm. 65, 2011, pp. 97 y ss., pp. 101 y 102

22 El ámbito de aplicación del artículo 8 bis del Texto Refundido de la Ley General Presupuestaria, introducido por el Real Decreto-ley 8/2011, se limita al ámbito de la Administración General del Estado y a determinadas entidades locales. 
vidad el órgano encargo de calcular esa tasa, conforme a la metodología utilizada por la Comisión Europea, de acuerdo con su normativa (artículo 12.3).

Al margen de consideraciones económico-financieras que exceden el objeto de este análisis jurídico-constitucional, debe advertirse que la inclusión de la regla de gasto en la regulación orgánica se hace sin cobertura en un precepto constitucional. Esto es, en el marco del desarrollo de los principios constitucionales de estabilidad presupuestaria y sostenibilidad financiera, el legislador incorpora el mecanismo del techo de gasto para el conjunto de las administraciones, pero no sobre la base de la nueva redacción del artículo $135 \mathrm{CE}$, lo que puede generar dificultades para su consideración como parámetro de constitucionalidad por parte del Tribunal Constitucional ante una eventual incumplimiento de la norma por las administraciones públicas. La legitimidad de la actividad del Estado para fijar un tope al gasto público podría encontrar cobertura en el marco de la competencia estatal en materia de planificación general de la economía (artículo 149.1.13 CE) y, por su conexión, en su competencia en materia de Hacienda general y Deuda pública (art. 149.1.14 CE), incluso en los títulos competenciales en el artículo 149.1.11 y $18 \mathrm{CE}$, pero no, como se ha indicado, en el artículo $135 \mathrm{CE}$. Porque este precepto constitucional encomienda a una ley orgánica el desarrollo de los principios de estabilidad presupuestaria y sostenibilidad financiera, reconociendo constitucionalmente la competencia del Estado en esta materia $^{23}$. De este modo, la regla de gasto siendo un mecanismo complementario para el logro de esos objetivos, al no haber sido constitucionalizada, si será necesario recurrir a los títulos competenciales del artículo 149.1 CE.

Por otra parte, la instrumentación del principio de sostenibilidad financiera se concreta en el artículo 13 LOEPSF, conforme al cual el volumen de deuda pública del conjunto de administraciones públicas no podrá superar el $60 \%$ del PIB nacional o el porcentaje que se establezca en las normas europeas. No obstante, ese límite podrá superarse en las mismas circunstancias en que son admisibles situaciones de déficit estructural: catástrofes naturales, recesión económica o situaciones de emergencia extraordinaria. A diferencia de la regulación sobre los

${ }^{23}$ Según afirma la STC 61/2001, de 1 de marzo, «La legitimidad constitucional de que el Estado, ex. arts. 149.1.13 y 156.1 en conexión con el art. 149.1.14 CE, establezca topes máximos en materias concretas a las Comunidades Autónomas en la elaboración de sus presupuestos se extiende, con igual fundamento, a la fijación de topes generales para dichos presupuestos, toda vez que la política presupuestaria es un instrumento de la política económica de especial relevancia, a cuyo través incumbe al Estado garantizar el equilibrio económico general» (STC 61/2001/4. Argumentación confirmada por las SSTC 134/2011/6 y 157/2011/4). Esta doctrina ha sido reiterada igualmente en las SSTC 185/2011, 186/2011, 187/2011, 188/2011 y 189/2011, de 26 de noviembre, y 195/2011 y 198/2011, de 13 de diciembre. 
límites déficit público, el legislador fija la distribución de los límites de deuda entre las distintas administraciones públicas (un 44 por ciento para la Administración General del Estado, un 13 por ciento para las Comunidades Autónomas y un 3 por ciento para las Corporaciones locales), y limita las posibilidades para realizar operaciones de endeudamiento a aquella administración pública que supere el porcentaje establecido. Además se prevé expresamente que las operaciones de crédito y de emisión de deuda pública por cualquier administración pública deben tener cobertura legal y, en todo caso, deberá atender a las exigencias y principios de estabilidad presupuestaria y de deuda pública contempladas en la propia ley orgánica. No obstante, conviene destacar que siguiendo el mandato constitucional, se establece un periodo transitorio (hasta el 2020), para alcanzar el objetivo de endeudamiento público del 60 por ciento marcado por la ley, como el de equilibrio presupuestario, periodo durante el cual se deberán cumplir las condiciones que permitan la reducción de la deuda pública y del déficit estructural ${ }^{24}$.

La sostenibilidad financiera se convierte así en un principio rector de la actuación del sector público, estableciendo para ello, además, la prioridad absoluta en el pago de los intereses y el capital de la deuda frente a cualquier otro gasto (artículo 14). Conforme a esta cláusula, la deuda pública de las administraciones públicas deberá ser incluida en el estado de gastos de sus presupuestos teniendo carácter prioritario siempre frente a todos los gastos. Esta regla consagrada en el texto constitucional ${ }^{25}$ ha sido objeto de acertadas críticas por cuanto su aplicación automática impide considerar y ponderar bajo los presupuestos del Estado social la satisfacción de necesidades sociales más urgentes ${ }^{26}$, además de lesionar el principio de autonomía financiera ${ }^{27}$. De modo que, la aplicación au-

${ }^{24}$ Disposición transitoria primera, conforme a la disposición adicional de la reforma del artículo 135 de la Constitución.

${ }^{25}$ Según el artículo 135.3 CE «3. El Estado y las Comunidades Autónomas habrán de estar autorizados por ley para emitir deuda pública o contraer crédito. Los créditos para satisfacer los intereses y el capital de la deuda pública de las Administraciones se entenderán siempre incluidos en el estado de gastos de sus presupuestos y su pago gozará de prioridad absoluta».

${ }^{26}$ Para G. CÁMARA es «enteramente rechazable desde la perspectiva de los principios que inspiran el Estado social y democrático de Derecho la recepción de esta cláusula «toda vez que podrán existir situaciones excepcionales que generen necesidades a las que haya que atender con recursos con carácter prioritario incluso al pago de la deuda», en «La reforma del artículo $135 \mathrm{CE}$ » op. cit. p. 180.

27 E. ÁLVAREZ CONDE estima que esta regla «puede llegar a condicionar todas las partidas presupuestarias, alterando, en este caso, todos los esquemas del Estado social y reflejando una «pérdida de soberanía financiera» en «La reforma del artículo 135 CE» op. cit., pp. 161 y 162. Frente a esto, una lectura positiva de la incorporación de estos criterios de gasto público en el Estado Social puede encontrarse en F. DE CARRERAS, «La reforma del art. 135 CE», op. cit. 
tomática de esta regla no sólo podrá generar situaciones paradójicas ${ }^{28}$, sino que también desplaza cualquier opción de política económica o social constitucionalmente legítima. Igualmente, para el logro de los objetivos básicos de política presupuestaria y económico financiera expresados por el legislador orgánico, se determinan los criterios de actuación en el conjunto de las administraciones públicas (artículo 15) y para cada una de las Comunidades Autónomas (artículo 16). En este contexto, se prevé además, la emisión de informes por parte del Gobierno sobre el grado de cumplimiento de los objetivos de estabilidad presupuestaria, de deuda pública y de la regla de gasto. Dichos informes, cuyo contenido tendrá carácter público, recaen tanto sobre el contenido del proyecto de Presupuestos, el Presupuesto inicial y su ejecución y respaldarán la adopción de medidas de carácter preventivo o, en su caso, correctivo, ante situaciones de riesgo o incumplimiento de los objetivos marcados (artículo 17).

Como puede apreciarse, los problemas que plantean las previsiones contenidas en estos preceptos son de índole diversa. Por un lado, se advierte una laguna en la regulación del procedimiento de aprobación parlamentaria del objetivo, que resulta inexplicable por sus evidentes efectos prácticos ${ }^{29}$. Por otro lado, la norma adolece de una falta de coherencia interna que hubiese sido fácilmente subsanable ${ }^{30}$. Pero, quizá el aspecto que resulta más llamativo de la regulación

p. 184; J. DE ESTEBAN, ibidem, p. 195. Para una visión compensadora de las exigencias de estabilidad presupuestaria y Estado de Bienestar, J.L. CASCAÑO, ibidem, pp. 192 y 193.

${ }^{28}$ Incluso, frente a gastos estructurales, como los gastos de personal. De ser correcta esta interpretación, no deja de resultar, cuando menos, llamativo el resultado. Porque una cosa es que la situación de endeudamiento de las administraciones públicas condicione por ejemplo, las políticas de incremento de plantilla de personal, y otra es que el pago de los salarios tenga que ceder frente al pago de la deuda pública.

${ }_{29}$ Conforme al artículo 15.6 LOEPSF, «El acuerdo del Consejo de Ministros en el que se contengan los objetivos de estabilidad presupuestaria y de deuda pública se remitirá a las Cortes Generales acompañado de las recomendaciones y del informe a los que se refieren los apartados 4 y 5 de este artículo. En forma sucesiva y tras el correspondiente debate en Pleno, el Congreso de los Diputados y el Senado se pronunciarán aprobando o rechazando los objetivos propuestos por el Gobierno. Si el Congreso de los Diputados o el Senado rechazan los objetivos, el Gobierno, en el plazo máximo de un mes, remitirá un nuevo acuerdo que se someterá al mismo procedimiento». El problema se hubiese resuelto utilizando las normas generales del procedimiento legislativo tal y como había previsto la Ley General de Estabilidad Presupuestaria (artículo 8.3): «si aprobado el objetivo de estabilidad por el Congreso de los Diputados el mismo fuese rechazado por el Senado, el objetivo se someterá a nueva votación del Congreso, aprobándose si éste lo ratifica por mayoría simple». Vid. Dictamen 164/2012, del Consejo de Estado. (apartado VIII.L)

${ }^{30}$ En el artículo 16 debía haberse suprimido la referencia al Gobierno, ya que la aprobación del objetivo de estabilidad presupuestaria corresponde a las Cortes Generales, conforme a lo dispuesto en el artículo 15. Ibidem. 
recae sobre los informes de cumplimiento de los objetivos de estabilidad presupuestaria, de deuda pública y de la regla de gasto, especialmente porque resulta cuestionable la intervención externa en el proceso de elaboración y ejecución de los presupuestos aprobados por el sector público y las implicaciones que la eventual adopción de medidas preventivas, correctivas e incluso coercitivas, conlleva para la autonomía financiera.

\section{MEDIDAS PREVENTIVAS, CORRECTIVAS Y COERCITIVAS}

Uno de los aspectos más controvertidos de la ley orgánica es la regulación del capítulo IV, relativo a las medidas contempladas para asegurar el cumplimiento de los objetivos de estabilidad presupuestaria por cuanto, en algunos extremos resulta difícilmente compatible con el principio de autonomía y puede conllevar consecuencias políticas y jurídicas severas ${ }^{31}$. El legislador orgánico contempla tres tipos de medidas, de carácter preventivo, correctivo y coercitivo, mediante las cuales el Estado podrá sancionar los incumplimientos de los límites de déficit y deuda pública por parte de las Comunidades Autónomas y las Corporaciones locales.

a) Respecto a las medidas preventivas, se regulan, por un lado, las denominadas «medidas automáticas de prevención» con las que pretende garantizar que al cierre del ejercicio, se cumpla con el objetivo básico de estabilidad presupuestaria. Para ello, la norma impone, no aconseja o faculta, que las administraciones públicas realicen un seguimiento del grado de cumplimiento de este objetivo en la ejecución de su presupuesto, y deberán ajustar el gasto público para evitar un incumplimiento (artículo 18.1). Se impone así un principio de actuación en la fase de ejecución presupuestaria de las administraciones públicas que, más que una medida de carácter preventivo, se trata de un mecanismo

31 Las dudas de constitucionalidad que arroja la regulación orgánica en este punto motivaron la solicitud de la opinión del Consejo de Garantías Estatutarias, expresada en el Dictamen 8/2012, de 2 de julio. Nos remitimos particularmente al fundamento jurídico tercero del dictamen, donde el Consell realiza un minucioso examen de constitucionalidad y estatutoriedad de los preceptos contenidos en el capítulo IV de la ley orgánica (artículos 18 a 26), del que se concluye la adecuación de la regulación orgánica a la autonomía financiera garantizada constitucional y estatutariamente. Igualmente ilustrativos son los argumentos expuestos en el voto particular formulado al dictamen por el consejero Jover Presa, al que se adhieren los consejeros Carrillo y Vernet Llobet. 
ordinario de articulación del principio de estabilidad presupuestaria ${ }^{32}$. En todo caso, la norma contempla, ahora sí, como medida automática de prevención, la imposibilidad de realizar operaciones de endeudamiento, salvo las de tesorería, en aquellos supuestos en que una administración pública rebase el 95 por ciento de los límites de deuda pública establecidos (artículo 18.2). Se establece pues, un «umbral de deuda de carácter preventivo» con el fin de evitar que se rebasen los límites establecidos de forma global y para cada administración pública en el artículo 13.1 LOEPSF $^{33}$.

Por otra parte, la ley prevé un mecanismo de alerta temprana que consiste en la advertencia de riesgo de incumplimiento de los objetivos de déficit y deuda pública y regla de gasto, que permitirá al Gobierno anticipar la adopción de medidas de corrección para evitar el riesgo (artículo 19). La regulación de esta denominada «advertencia de riesgo de incumplimiento» presenta algunos problemas. Y es que, por un lado, la previsión se construye sobre un concepto jurídico indeterminado (el «riesgo de incumplimiento») cuya apreciación corresponde al Gobierno quien formulará una advertencia motivada a la Comunidad Autónoma o a la Corporación local en riesgo de incumplimiento, dando cuenta de ello para su conocimiento al Consejo de Política Fiscal y Financiera o a la Comisión Nacional de Administración Local, según corresponda ${ }^{34}$. La intervención de estos órganos de carácter consultivo y deliberativo, pero con un papel esencial de coordinación entre el Estado y las Comunidades Autónomas y de colaboración entre el Estado y las Corporaciones Locales, respectivamente, sobre las actividades financieras en materia de política presupuestaria, endeudamiento o inversión pública, entre otras actuaciones ${ }^{35}$, se limita en este supuesto a conocer

32 De ahí que el Consejo de Estado aconsejara reubicar este contenido del precepto en el artículo 11 relativo a la instrumentación del principio de estabilidad presupuestaria. Vid. Dictamen 164/2012, del Consejo de Estado. (apartado IX.A.1)

33 Exposición de Motivos de la LOEPSF.

${ }^{34}$ Conforme a la redacción del apartado $1^{\circ}$ del artículo 19 LOEPSF «1. En caso de apreciar un riesgo de incumplimiento del objetivo de estabilidad presupuestaria, del objetivo de deuda pública o de la regla de gasto de las Comunidades Autónomas o de las Corporaciones Locales, el Gobierno, a propuesta del Ministro de Hacienda y Administraciones Públicas, formulará una advertencia motivada a la Administración responsable previa audiencia a la misma. Formulada la advertencia el Gobierno dará cuenta de la misma para su conocimiento al Consejo de Política Fiscal y Financiera, si la advertida es una Comunidad Autónoma, y a la Comisión Nacional de Administración Local, si es una Corporación Local. Dicha advertencia se hará pública para general conocimiento».

35 Vid. artículo 3.2 a), d), e), f) y g) de la Ley Orgánica de Financiación de las Comunidades Autónomas. Para la naturaleza y competencias de la Comisión Nacional de Administración Local, vid. arts. 117, 118 y 119 de la Ley 7/1985, de 2 de abril, reguladora de las Bases del Régimen 
a posteriori de la advertencia realizada por el Gobierno ${ }^{36}$. Con esta participación de alcance tal restringido, el legislador orgánico vuelve a desaprovechar la ocasión, como ya lo hiciera respecto a los informes de cumplimiento de los objetivos de déficit, deuda pública y techo de gasto, para rodear la actuación del Gobierno de mayores garantías en aras del respeto al principio de autonomía. Porque, si la participación de estos órganos se hubiese previsto con carácter previo a la formulación de la advertencia, tal y como sugirió el Consejo de Estado, se hubiese logrado una mayor compatibilidad entre las exigencias de celeridad que informan la adopción de estas medidas y el respeto a la autonomía ${ }^{37}$. Pero, la preocupación legislativa por la adopción rápida de medidas culmina con la facultad estatal para aplicar medidas correctivas ante la inexistencia o insuficiencia de repuesta por parte de la administración responsable del eventual riesgo de incumplimiento ${ }^{38}$. A nuestro juicio, hubiese sido deseable una mayor ponderación entre los principios antes mencionados, donde en todo caso se evitara el desequilibrio que produce la norma en perjuicio de la autonomía política y municipal en aras de una actuación estatal rápida y, por ello, presuntamente, más eficaz. Y es que, a pesar de las circunstancias políticas y económicas que rodean esta regulación, es necesario encontrar fórmulas legislativas que salvaguarden principios esenciales de nuestro sistema constitucional.

b) Respecto a las medidas correctivas, la regulación orgánica prevé «medidas automáticas de corrección» conforme a las cuales el cumplimiento de los objetivos de estabilidad constituye un criterio determinante para la autorización de emisiones de deuda, la concesión de subvenciones o la suscripción de convenios (artículo 20). Estas medidas podrán ser adoptadas en tres supuestos distintos: a) aquellos en los que exista riesgo de incumplimiento apreciado por el Gobierno conforme a los informes sobre el grado de cumplimiento de los objetivos de estabilidad presupuestaria, de deuda pública y de regla de gasto; b) supuestos en los que se constate una situación de incumplimiento de los objetivos antes mencionados, y c) supuestos en los que el Gobierno haya formulado una advertencia por riesgo de incumplimiento de los objetivos de estabilidad

Local y Decreto 427/2005, de 15 de abril, por el que se regula la composición, funciones y funcionamiento de la Comisión Nacional de Administración Local.

36 Artículo 17.4 LOEPSF.

37 Dictamen 164/2012, del Consejo de Estado [apartado IX. A. 2.a)].

38 Según el artículo 19.2 LOEPSF «La Administración advertida tendrá el plazo de un mes para adoptar las medidas necesarias para evitar el riesgo, que serán comunicadas al Ministerio de Hacienda y Administraciones Públicas. Si no se adoptasen las medidas o el Ministro de Hacienda y Administraciones Públicas aprecia que son insuficientes para corregir el riesgo, se aplicarán las medidas correctivas previstas en los artículos 20 y 21 y 25, apartado 1.a)». 
presupuestaria, de deuda pública y de regla de gasto. Se advierte, no obstante, consecuencias diferentes según el tipo de administración responsable o potencialmente responsable del incumplimiento. En los supuestos en que sea una Comunidad Autónoma, todas sus operaciones de endeudamiento estarán sometidas a autorización del Estado ${ }^{39}$, mientras que si el incumplimiento procede de una corporación local ${ }^{40}$, sólo se verán afectadas por la autorización del Estado o la Comunidad Autónoma según corresponda, las operaciones de endeudamiento a largo plazo.

Por otra parte, ante los supuestos de incumplimiento de los objetivos de estabilidad presupuestaria, se prevé que la administración responsable presente un plan económico financiero que, en el plazo de un año, permita corregir las desviaciones presupuestarias (artículo 21). En todo caso, se distinguen los supuestos en que dichas desviaciones se produzcan por circunstancias excepcionales (catástrofes naturales, recesión económica o situaciones de emergencia extraordinaria), supuestos que conducen a la presentación de un Plan de equilibrio que permita restaurar la situación económico-financiera, mediante la adopción de medidas adecuadas con las que lograr los objetivos de estabilidad presupuestaria y deuda pública (artículo 22) ${ }^{41}$. La tramitación y seguimiento de los planes económico-financieros y de reequilibrio y los informes de seguimiento a los que están sometidos, si bien son regulados de forma unitaria (artículos 23 y 24), presentan diferencias, según afecten a la Administración General del Estado, las Comunidades Autónomas o las Corporaciones locales. Así, para el ámbito de la Administración General del Estado, los planes serán elaborados por el Gobierno y aprobados por las Cortes Generales. En cambio, en los planes elaborados por

39 «No obstante, si la Comunidad Autónoma hubiera presentado un plan económicofinanciero considerado idóneo por el Consejo de Política Fiscal y Financiera, las operaciones de crédito a corto plazo que no sean consideradas financiación exterior no precisarán de autorización del Estado» (artículo 20.1 párrafo segundo LOEPSF).

${ }^{40}$ En todo caso, la norma sólo es aplicable a las corporaciones locales incluidas en el ámbito subjetivo de los artículos 111 y 135 del Texto Refundido de la Ley Reguladora de las Haciendas Locales, aprobada por Real Decreto Legislativo 2/2004, de 5 de marzo. Conforme al primer precepto, la norma afecta a los municipios a) que sean capitales de provincia o de Comunidad Autónoma, o b) que tengan población de derecho igual o superior a 75.000 habitantes. Dentro del segundo de los preceptos citados del TRLRHL, se incluyen las provincias y entes asimilados a estos efectos (Comunidades Autónomas uniprovinciales no insulares, islas y Ciudades Autónomas de Ceuta y Melilla).

41 Debe advertirse, con el Consejo de Estado, el grado de indeterminación sobre cuándo, cómo y quién debe constatar la existencia una situación de incumplimiento de los objetivos de estabilidad, de deuda y regla de gasto que habilite la activación de estas medidas correctivas o los mecanismos descritos para su corrección o reequilibrio. Vid. Dictamen 164/2012, del Consejo de Estado (apartado IX. B.1 y 2). 
las Comunidades Autónomas interviene el Consejo Política Fiscal y Financiera, órgano encargado de comprobar la idoneidad de las medidas incluidas y la adecuación de las medidas previstas para corregir la situación de desequilibrio. Por último, para el ámbito de la administración local, corresponde con carácter general al Pleno de la Corporación aprobar el plan, si bien para los municipios incluidos en el ámbito de aplicación de los artículos 111 y 135 del TRLRHL, será el Gobierno el órgano encargado de su aprobación, salvo que la Comunidad Autónoma donde se encuentre radicado el municipio tenga competencias estatutarias para la tutela financiera de las corporación local, en cuyo caso, será ésta quien apruebe de forma definitiva el plan, remitiendo posterior informe al Gobierno sobre su aprobación y seguimiento. En todo caso, los planes adoptados para las corporaciones locales serán remitidos a la Comisión Nacional de Administración Local para su conocimiento.

Al margen de estas diferencias, el procedimiento descrito contiene algunos extremos que deben ser aclarados por cuanto pueden arrojar interrogantes desde la perspectiva de su aplicación práctica. En efecto, la intervención del órgano de coordinación multilateral en materia financiera, esto es, el Consejo de Política Fiscal y Financiera, para requerir la presentación de un nuevo plan a las Comunidades Autónomas cuando las medidas contenidas no garanticen la corrección del desequilibrio, resulta constitucionalmente legítima pues se trata de medidas que pueden afectar al conjunto del Estado ${ }^{42}$. Sin embargo, las consecuencias previstas para los casos de falta de presentación del plan o la inadecuación de las medidas previstas a los objetivos marcados, esto es, la aplicación de las medidas coercitivas del artículo 25, si pueden ser cuestionables. No tanto porque no encuentren cobertura constitucional para su adopción, que si la tienen, aún más si cabe en el nuevo artículo $135 \mathrm{CE}$, sino porque su articulación puede resultar difícil ${ }^{43}$.

Más cuestionable, desde el punto de vista del reparto constitucional de competencias, resulta la regulación relativa a los informes de seguimiento de los planes sobre la aplicación de las medidas para corregir las desviaciones y cumplir los objetivos de estabilidad. Dicha regulación atribuye al Gobierno la emisión de los citados informes, que dará traslado al Consejo de Política Fiscal y Financiera o, en su caso, a la Comisión Nacional de Administración Local para su mero conocimiento. El incumplimiento persistente de los objetivos de estabilidad generará la aplicación de las medidas coercitivas a la administración responsable (artículo 24). El problema constitucional se plantea pues, como

42 STC 134/2011/11, de 20 de julio, reiterada en STC 198/2011/4, de 13 de diciembre.

43 Vid. el Dictamen 164/2012, del Consejo de Estado. (apartado IX. B. 3 c). 
advierte el Consejo de Estado, según se desprende del artículo 135 CE y de la jurisprudencia constitucional se debía haber otorgado una mayor participación del Consejo de Política Fiscal y Financiera en este procedimiento, pues «es el órgano que traduce o en el que se refleja el marco constitucional de coordinación y cooperación entre el Estado y las Comunidades Autónomas en materia financiera, por lo que parece razonable atribuirle la apreciación de las circunstancias que pueden desembocar en la aplicación de las medidas coercitivas» ${ }^{44}$. No obstante, hay un matiz a considerar y es que «ello debe entenderse sin perjuicio de que pueda atribuirse el poder último de decisión al Gobierno cuando esté en juego el cumplimiento de las normas de la Unión Europea y para garantizar su efectivo cumplimiento» ${ }^{45}$. Entendemos, sin embargo, que la gravedad de la sanción que puede recaer sobre una Comunidad Autónoma derivada de un incumplimiento de sus compromisos con los objetivos de estabilidad y deuda pública, respalda la intervención del Consejo de Política Fiscal y Financiera en lugar del Gobierno. De este modo, además, el respeto al reparto constitucional de competencias queda garantizado y, ello no impide, en última instancia, la ejecución y cumplimiento del derecho europeo. Es más, de este modo se impediría una alteración del reparto competencial por la vía de las obligaciones derivadas de la aplicación de los compromisos europeos.

c) Por último, es necesario destacar los elementos esenciales de la regulación sobre las medidas coercitivas, uno de los ámbitos donde la ley orgánica plantea elementos para su reflexión, por cuanto la adopción de algunas de ella puede conllevar graves consecuencias jurídicas y lesionar la autonomía financiera constitucionalmente garantizada. Estas medidas coercitivas consisten en: a) la indisponibilidad de los créditos por parte de la administración responsable de la falta o incumplimiento del plan económico-financiero, b) el traspaso al Estado de las competencias normativas autonómicas sobre los tributos cedidos, c) la constitución de un depósito con intereses en el Banco de España equivalente al 0,2 por ciento de su PIB nominal, que se podrá convertir en multa coercitiva en caso de persistir el incumplimiento transcurrido seis meses desde su constitución, d) la intervención de una comisión de expertos que, tras la valoración de la situación económico financiera de la administración, presentará una conclusiones y propondrá medidas de actuación de obligado cumplimiento. Además, durante la ejecución de las medidas propuestas por la comisión de expertos, la administración no podrá autorizar ninguna operación de crédito ni acceder a mecanismos de financiación (artículo 25).

\footnotetext{
44 Vid. el Dictamen 164/2012, del Consejo de Estado, (apartado IX. B.3 d).

45 Ibidem.
} 
La extensión e intensidad de estas medidas sobre las facultades de actuación de la administración incumplidora es más que notable. No sólo se impide la disposición de fondos económicos, limitando las facultades económico-financieras de la administración responsable, sino que suprime el ejercicio de las competencias normativas de las Comunidades Autónomas legítimamente asumidas en el marco de las correspondientes previsiones contenidas en los EEAA y la LOFCA, lo que resulta difícilmente compatible con la autonomía financiera garantizada constitucionalmente ${ }^{46}$. La constitución de un depósito en el Banco de España es, en cambio, una medida que incorporada del derecho europeo ${ }^{47}$ resulta coherente con la situación de desequilibrio que genera o puede generar el incumplimiento. Pero lo que resulta más sorprendente es la previsión de la intervención de una comisión de expertos para evaluar la situación económica de la administración responsable. A pesar de la novedad que supone en nuestro sistema la intervención de esta comisión en la fiscalización de las cuentas públicas $^{48}$, el legislador deja muy poco definida la naturaleza y composición de esta comisión, sobre la que sólo fija su dependencia del Gobierno ${ }^{49}$, centrando su regulación en la función fiscalizadora para la que deberá contar con toda la información sobre la situación contable de la administración que hará pública en una semana, mediante un informe de conclusiones. Al margen de la eventual eficacia práctica que pueda tener la adopción de esta medida para lograr los objetivos de la ley y, por tanto, restablecer el equilibrio presupuestario, no cabe desconocer el impacto político y económico que puede generar en el conjunto del Estado la intervención de una administración pública por esta vía.

${ }^{46}$ La posición mayoritaria del Consell de Garanties Estatutaries de Cataluña expuesta en el dictamen 8/2012, mantiene que esta medida constituye «un desplazamiento excepcional» del ejercicio de las competencias normativas pues «se limita a establecer la suspensión temporal de su ejercicio hasta que desaparezcan los supuestos que dan lugar a su activación» (fundamento jurídico tercero, apartado 4.D). Frente a estas consideraciones, el voto particular al dictamen sostiene que dicha medida por un lado, modifica el régimen de cesión de tributos a las Comunidades Autónomas al margen del procedimiento estatutario y legal y, por otro, presupone la adopción de los instrumentos normativos necesarios «que garanticen incrementos en la recaudación encaminados a corregir las desviaciones producidas en el déficit. Y como se sabe, estos cambios no producen efectos inmediatos» (pp. 53 y 54).

47 Artículo 126.11 del TFUE y artículo 12 del Reglamento (CE) no 1467/1997, de 7 de julio.

48 Se trata de una medida incorporada del derecho europeo, en particular del artículo 10.bis del Reglamento (CE) 1467/1997, incluido por el Reglamento (UE) n $\mathrm{n}^{\circ}$ 1177/2011 del Consejo, de 8 de noviembre de 2011, regulador de las misiones de supervisión de la situación económica real de los Estados miembros.

49 Vid. Dictamen 164/2012, del Consejo de Estado (apartado IX. C.1). 
Pero, si comprometidas pueden ser las consecuencias políticas y económicas derivadas de estas medidas y lesivas de la autonomía financiera del poder público intervenido, más severas y cuestionables desde la perspectiva constitucional resulta cualquiera de las sanciones previstas en el artículo 26. Conforme a este precepto, la no adopción de las medidas impuestas en el artículo anterior faculta al Estado para obligar a una Comunidad Autónoma o a una Corporación local a su cumplimiento forzoso. Dicha facultad estatal se contempla igualmente, ante la situación de riesgo por incumplimiento del pago de los vencimientos de deudas financieras (disposición adicional cuarta) ${ }^{50}$. De este modo, si la administración incumplidora es una Comunidad Autónoma, la intervención del Estado prevista por el legislador orgánico se ampara en el artículo 155 de la Constitución, mecanismo constitucional de naturaleza muy excepcional, formulado para preservar el interés general frente a actuaciones lesivas de las Comunidades Autónomas. El carácter extremo de esta medida justifica su consideración restrictiva y, por ello, resulta difícilmente admisible una ampliación de las condiciones o facultades para su adopción ${ }^{51}$. Pero no es esa la opción tomada por el legislador orgánico que, al incorporar el mecanismo del artículo $155 \mathrm{CE}$, amplía las facultades de control del Gobierno quien, en caso de no atenderse el requerimiento adoptará, con la aprobación por mayoría absoluta del Senado, las medidas necesarias para obligar a la Comunidad Autónoma a su ejecución forzosa. Esto es, el legislador convierte en obligación del Gobierno una mera potestad constitucional.

Finalmente, la norma reproduce este esquema, con las adaptaciones necesarias respecto a los órganos que intervienen en el procedimiento, para los supuestos en que la administración incumplidora sea una corporación local. La ley contempla la posibilidad de disolver los órganos de una corporación local cuando la persistencia en el incumplimiento de las obligaciones de estabilidad, deuda pública y regla de gasto sea considerada «gravemente dañosa para los intereses generales». La adopción de esta medida, cuyo presupuesto de hecho consiste en una «gestión gravemente dañosa» derivada de un persistente in-

${ }^{50}$ Conforme a esta disposición adicional, introducida por la Ley Orgánica 4/2012, de 28 de septiembre, de modificación de la LOEPSF, «1. Las Administraciones Públicas deberán disponer de planes de tesorería que pongan de manifiesto su capacidad para atender el pago de los vencimientos de deudas financieras con especial previsión de los pagos de interés y capital de la deuda pública. 2. La situación de riesgo de incumplimiento del pago de los vencimientos de deuda financiera, apreciada por el Gobierno a propuesta del Ministro de Hacienda y Administraciones Públicas, se considera que atenta gravemente al interés general procediéndose de conformidad con lo dispuesto en el artículo 26».

51 Dictamen 164/2012, del Consejo de Estado (apartado IX. C. 2). 
cumplimiento de las obligaciones constitucionales, resulta amparada en el artículo 61 de la Ley 7/1985 LRBRL $^{52}$. El alcance de esta sanción consiste, en definitiva, en suprimir el ejercicio de una autonomía constitucionalmente reconocida a los entes locales (artículo $137 \mathrm{CE}$ ) motivada, según el legislador, en la incapacidad para gestionar sus intereses y lesiva para el conjunto del Estado. A nuestro juicio, la desproporción entre el presupuesto de hecho y las consecuencias previstas resta legitimidad a esta previsión como a la prevista en el apartado primero y, en todo caso, aconseja extremar la prudencia a la hora de valorar su aplicación.

\section{GESTIÓN PRESUPUESTARIA}

La definición de un marco presupuestario a medio plazo, el establecimiento de un límite al gasto no financiero para el conjunto de las administraciones públicas, la previsión de un fondo de contingencia o la vinculación del superávit presupuestario a determinados fines, constituyen otros aspectos regulados en la ley (capítulo VI). En este contexto, el legislador impone a las administraciones públicas la elaboración de un marco presupuestario ajustado a la normativa europea $^{53}$, que abarcará un periodo de tres años con el fin de garantizar una programación presupuestaria coherente con los objetivos básicos de estabilidad presupuestaria y de deuda pública y que servirán de base para la elaboración del Programa de Estabilidad (artículo 29). De nuevo, en aras de la coherencia con el cumplimiento de los objetivos de la ley, ahora de estabilidad presupuestaria y la regla de gasto, la ley impone la obligación para todas las administraciones públicas de fijar anualmente un límite máximo de gasto no financiero, que

52 Conforme a este precepto «1. El Consejo de Ministros, a iniciativa propia y con conocimiento del Consejo de Gobierno de la Comunidad Autónoma correspondiente o a solicitud de éste y, en todo caso, previo acuerdo favorable del Senado, podrá proceder, mediante Real Decreto, a la disolución de los órganos de las corporaciones locales en el supuesto de gestión gravemente dañosa para los intereses generales que suponga incumplimiento de sus obligaciones constitucionales. 2. Se considerarán, en todo caso, decisiones gravemente dañosas para los intereses generales en los términos previstos en el apartado anterior, los acuerdos o actuaciones de los órganos de las corporaciones locales que den cobertura o apoyo, expreso o tácito, de forma reiterada y grave, al terrorismo o a quienes participen en su ejecución, lo enaltezcan o justifiquen, y los que menosprecien o humillen a las víctimas o a sus familiares. 3. Acordada la disolución, será de aplicación la legislación electoral general, cuando proceda, en relación a la convocatoria de elecciones parciales y, en todo caso, la normativa reguladora de la provisional administración ordinaria de la corporación».

53 Vid. al respecto los artículo 9 y ss. de la Directiva 2011/85/UE del Consejo, de 8 de noviembre de 2011, sobre los requisitos aplicables a los marcos presupuestarios de los Estados miembros. 
marcará el techo de la asignación de los recursos presupuestarios (artículo 30). Por otra parte, las administraciones públicas deberán dotar una partida presupuestaria destinada a atender necesidades de carácter no discrecional y no previstas en el presupuesto inicial (artículo 31). Por último, la norma contempla la obligación de destinar el superávit presupuestario a reducir la deuda pública, si bien en el caso de que dicho superávit se produzca en el presupuesto de la Seguridad Social, éste se destinará prioritariamente a aumentar el Fondo de Reserva (artículo 32). Se impone pues, una serie de obligaciones que pretenden evitar problemas para el cumplimiento de los objetivos de estabilidad presupuestaria, límites al endeudamiento público y el techo de gasto, en la línea marcada por las normas europeas. Pero, si bien esta regulación resulta coherente con los objetivos básicos de la norma, no cabe desconocer que la rigidez de algunos de sus extremos, en particular, el referente al destino del superávit, resulta difícilmente compatible con la autonomía financiera de las administraciones públicas ${ }^{54}$. Porque la actuación financiera de las administraciones públicas aparece condicionada por el único objetivo de disminuir el endeudamiento público obligando con ello a dejar al margen otros objetivos económicos o sociales plenamente legítimos.

\section{CONCLUSIONES}

La Ley Orgánica de Estabilidad Presupuestaria y Sostenibilidad Financiera desarrolla el contenido del artículo 135 CE dando así cumplimiento al mandato constitucional con el que se pretende asegurar que todas las administraciones públicas actúen conforme a las exigencias constitucionales de estabilidad presupuestaria y limite de deuda pública. Este desarrollo legislativo traduce de forma bastante fiel el compromiso del Estado español con el marco europeo de estabilidad y gobernanza económica, sometiendo al conjunto de las administraciones públicas a un régimen jurídico rígido orientado al cumplimiento de los límites de déficit y deuda pública. En este contexto normativo, el Estado actúa como garante último del logro de esos objetivos, limitando incluso, a veces, el pleno desarrollo del principio de autonomía financiera. No cabe duda de los beneficios

${ }^{54}$ Así lo ha entendido también el Consejo de Garantías Estatutarias para quien la Constitución «no habilita al legislador para introducir un mandato que limita de manera desproporcionada la autonomía financiera de las comunidades autónomas sin que sea necesario para la consecución del objetivo de estabilidad presupuestaria». (Dictamen 8/2012, de 2 de julio, sobre la Ley Orgánica 2/2012, de 27 de abril de estabilidad presupuestaria y sostenibilidad financiera, fundamento jurídico cuarto.5). 
económicos que conlleva la regulación orgánica, en aras de una mayor responsabilidad en la gestión de los recursos económicos por el conjunto de las administraciones públicas. Pero también es cierto que los compromisos adoptados en el ámbito europeo en materia de estabilidad presupuestaria y sostenibilidad financiera y su consiguiente traducción en la legislación interna, pueden dejar en suspenso funciones esenciales del Estado. Y es que, a la luz de los últimos textos normativos aprobados en el marco de la situación económica actual, la actuación del poder público aparece condicionada por objetivos de naturaleza económica, que desplazan la función social del Estado en aras de una gestión más eficaz de los recursos económicos y las finanzas públicas. Este efecto es particularmente preocupante en un contexto social y económico donde la intervención del poder público resulta más que aconsejable para garantizar necesidades básicas del individuo y el ejercicio de derechos sociales.

Title:

ORGANIC ACT OF STABILITY BUDGET AND FISCAL SUSTAINABILITY. THE REQUIREMENT OF PUBLIC SECTOR BUDGET STABILITY

\begin{abstract}
Resumen:
El presente estudio realiza un análisis crítico de los principales contenidos de la Ley Orgánica 2/2012, de 27 de abril, de Estabilidad Presupuestaria y Sostenibilidad Financiera, mediante la cual se da cumplimiento al mandato constitucional previsto en el artículo $135 \mathrm{CE}$, con el que se pretende asegurar que todas las administraciones públicas actúen conforme a las exigencias de estabilidad presupuestaria y limitación del endeudamiento público. El objeto de este estudio conduce a la exposición en primer lugar, de las novedades respecto de los principios generales en esta materia, en segundo lugar, de las reglas para la instrumentación de los principios de estabilidad presupuestaria y sostenibilidad financiera, en tercer lugar se analizan las medidas de carácter preventivo, correctivo y coercitivo establecidas para garantizar el cumplimiento de los objetivos de equilibrio presupuestario y de deuda pública desarrollados por el legislador, y por último, se destacan las criterios adoptados en materia de gestión presupuestaria. La
\end{abstract}


exposición de estos contenidos conducirá, finalmente, a una reflexión global sobre el alcance de esta actuación del legislador orgánico.

\title{
Palabras clave:
}

Constitución, Unión Europea, Estabilidad Presupuestaria, Sostenibilidad Financiera.

\begin{abstract}
:
This paper analyzes the main contents of the Organic Act 2/2012 of 27 April on Budgetary Stability and Financial Sustainability of development of Article 135 EC, which aims to ensure that all public authorities act in accordance with the requirements budgetary stability and limitation of the public debt. With this object is exposed on one side, the developments concerning the general principles in this matter, secondly, the rules for implementing the principles of budgetary stability and financial sustainability, in third place, we analyze the preventive measures, remedial and coercive in place to ensure compliance with the objectives of balanced budgets and public debt, and finally, it highlights the criteria for budget management. These contents will lead to a global reflection on the scope of this Act.
\end{abstract}

Key words:

Constitution, European Union, Budgetary Stability, Financial Sustainability. 